\title{
Análise do perfil da autorregulação da aprendizagem de alunos de pedagogia EaD
}

\section{(An analysis of the profile of students' learning self- regulation in distance learning pedagogy course)}

\author{
Juliana Gomes Fernandes \\ Instituto Federal do Paraná, IFPR (Brasil) \\ Luciane G. Batistella Bianchini \\ Universidade Norte do Paraná, UNOPAR (Brasil) \\ Paula M. Zedu Alliprandini \\ Universidade Estadual de Londrina, UEL (Brasil)
}

DOI: http://dx.doi.org/10.5944/ried.23.1.24029

\section{Como referenciar este artigo:}

Gomes-Fernandes, J., Batistella Bianchini, L. G., y Zedu Alliprandini, P. M. (2020). Análise do perfil da autorregulação da aprendizagem de alunos de pedagogia EaD. RIED. Revista Iberoamericana de Educación a Distancia, 23(1), pp. 269-286. doi: http://dx.doi.org/10.5944/ried.23.1.24029

\section{Resumo}

A Educação a Distância (EaD) é uma modalidade de ensino que exige maior responsabilidade e comprometimento por parte do aluno, que necessita ter grande autonomia sobre seu processo de aprendizagem. Tais aspectos suscitam reflexões e questionamentos acerca do perfil do aluno matriculado na $\mathrm{EaD}$ e, portanto, a presente pesquisa analisou o perfil de aprendizagem autorregulada dos alunos matriculados em um curso de Pedagogia a distância de uma universidade privada. Trata-se de uma pesquisa de campo, descritiva, com abordagem quantitativa. Participaram da pesquisa 1.434 alunos, que responderam a escala Questionário de Aprendizagem Autorregulada Online desenvolvida por Barnard-Brak, Lan e Paton (2010). Os participantes apresentaram um perfil alto de autorregulação, nos fatores estabelecimento de metas e estruturação do ambiente, e moderado nos fatores estratégias para as tarefas, gerenciamento do tempo, procura por ajuda e autoavaliação. Quanto maior a faixa etária mais autorregulado se apresentou o aluno. Pretende-se dessa forma auxiliar o corpo docente e os tutores do curso pesquisado a reconhecerem o perfil dos seus alunos nos aspectos relacionados à autorregulação da aprendizagem, podendo dessa maneira orientá-los em qual direção seguir para melhoria de sua prática pedagógica, bem como contribuir para uma melhor articulação dos projetos pedagógicos aos processos educacionais de aprendizagem no contexto de cursos a distância. 
Palavras-chave: autorregulação; aprendizagem; educação a distância; pedagogia.

\begin{abstract}
Distance Education (DE) is a type of education that requires greater responsibility and commitment on the part of the student who will need to have great autonomy over their learning process. These aspects raise reflections and questions about the profile of the student enrolled in DE and, therefore, the present study examined the self-regulated learning profile of students enrolled in a Distance Education Pedagogy School from a private university. This is a field research, descriptive, with quantitative approach. The participants were 1,434 students who answered the scale Self-regulated Learning Online Questionnaire developed by Barnard-Brak, Lan and Paton (2010). The participants have a high self-regulation pattern, regarding setting goals and structuring the environment, and moderate regarding strategies for tasks, time management, search for help and self-assessment. The older the person, the more self-regulated the student is. Thus, the objective is to assist the researched faculty and course tutors to recognize the profile of their students regarding learning self-regulation, thus guiding them in which direction to follow in order to improve their pedagogical practice, as well as contributing for a better articulation of educational projects to educational learning processes in the context of distance learning courses.
\end{abstract}

Keywords: self-regulation; learning; distance education; pedagogy.

Conforme dados da Associação Brasileira de Educação a Distância (2018), de 2015 para 2017 houve um crescimento de $53 \%$ no número de matrículas nos cursos de graduação ofertados nesta modalidade, totalizando em 2017, 7.723.828 matrículas. Tal evolução se dá pela capilaridade da $\mathrm{EaD}$, possibilitando à modalidade atender indivíduos nas mais diferentes localidades e/ou que não teriam acesso ao ensino superior, sendo inegável sua contribuição ao cenário educacional atual (Alves, 2011).

Se por um lado, a EaD possibilita a democratização do ensino, por outro, exige maior responsabilidade e comprometimento do aluno, que necessita ter grande autonomia sobre seu processo de aprendizagem, podendo controlar seu ritmo de estudo, personalizar uma série de aspectos e realizar escolhas que podem auxiliar seu desenvolvimento cognitivo (Testa e Luciano, 2010).

Nessa modalidade, na qual a presencialidade é modificada e tecnologias adicionais são incorporadas ao processo, para que a aprendizagem aconteça, o aluno, além de conhecer as ferramentas utilizadas, deve possuir ou desenvolver características e comportamentos, como: organização, motivação, determinação, autonomia, disciplina, responsabilidade, capacidade de agir e pensar independentemente, fazer escolhas acertadas, ser capaz de pensar em sua própria aprendizagem e saber controlá-la frente uma nova informação (Benício, 2010; Lessa, 2011).

$\mathrm{O}$ aluno tem que movimentar-se para construir a própria aprendizagem, não podendo mais supor que ela só acontece a partir de uma aula dada (Lima, 2003). Ele 
precisa ser cada vez mais independente e responsável, estar apto a discutir e a refletir, resolver e buscar soluções para as dificuldades encontradas, tendo consciência de sua ativa participação nas diferentes situações de aprendizagem (Góes e Alliprandini, 2013).

Portanto, pode-se inferir que as características do indivíduo podem afetar a aprendizagem a distância, e nesse sentido pesquisadores têm considerado a utilização de estratégias de aprendizagem, principalmente as que indicam uma aprendizagem autorregulada como de fundamental importância para seu êxito na EaD (BarnardBrak, Lan, e Paton, 2010; Bergamin, Ziska, Werlen e Siegenthaler, 2012; Dias e Leite, 2010; Góes e Alliprandini, 2014; Piccoli, Ahmad e Ives, 2001).

A autorregulação da aprendizagem é estudada pela Teoria Social Cognitiva, que a entende como um processo dinâmico que envolve fatores pessoais, variáveis do meio e ação ou comportamento do indivíduo. Segundo Zimmermam (2000), a autorregulação pode ser compreendida como o grau de participação ativa dos alunos na sua aprendizagem, englobando aspectos metacognitivos, motivacionais e comportamentais.

Refletindo sobre o contexto apresentado acima, bem como visando compreender melhor alguns aspectos da aprendizagem do aluno na EaD, este trabalho tem como objetivo analisar o perfil da aprendizagem autorregulada dos alunos matriculados no curso de Pedagogia ofertado a distância de uma instituição particular.

\section{AUTORREGULAÇÃO DA APRENDIZAGEM E EAD}

A autorregulação da aprendizagem é um tema que tem despertado interesse de vários autores de diferentes abordagens da Psicologia, sempre com o intuito de tentar compreender e explicar esse importante constructo da aprendizagem humana. Apesar de alguns pontos de discordância entre os diversos autores, há um consenso de que a autorregulação da aprendizagem se refere ao grau em que os estudantes ativam metacognitiva, motivacional e comportamentalmente seu próprio processo de aprendizagem (Simão e Frison, 2013; Zimmerman e Schunk, 2011).

Esse constructo é considerado um processo cíclico e multidimensional, inerente a todos os seres humanos, no qual o estudante desempenha um papel ativo, num processo diferenciado de acordo com as exigências de cada situação, sendo uma ação intencional, planejada, temporal, dinâmica e complexa (Silva, Simão e Sá, 2004; Simão e Frison, 2013).

Considera-se intencional, pois sempre parte de um objetivo ou meta a ser alcançado. Planejada, devido ao fato de depender de um planejamento estratégico das ações, sejam elas cognitivas, metacognitivas ou motivacionais. Temporal, por se desenvolver por determinado período de tempo até o alcance do objetivo. É um processo dinâmico, pois pode se alterar ao longo das fases e complexo, à medida que não é linear, e envolve variáveis cognitivas, metacognitivas, motivacionais e 
socioemocionais que a vão mediar ou moderar, positiva ou negativamente (Simão e Frison, 2013).

Lynch e Dembo (2004) analisaram a autorregulação como preditivo de sucesso na $\mathrm{EaD}$, e encontraram que o senso de autoeficácia estava relacionado com o desempenho, bem como a capacidade de gestão do tempo e do ambiente de estudos, confirmando a suposição inicial de que a capacidade de autorregulação influencia positivamente no aproveitamento dos alunos. No mesmo sentido, Vovides et al. (2007), afirmam que o processo de ensino realizado em ambientes virtuais de aprendizagem deve objetivar a autorregulação da aprendizagem, proporcionando ao aluno condições de desenvolver estratégias cognitivas e metacognitivas, por meio de estratégias didáticas que contemplem as especificidades da EaD. Sabourin, Mott e Lester (2012) completam, que comportamentos de aprendizagem autorregulados, como estabelecimento de metas e automonitoramento, são essenciais para o sucesso dos alunos em ambientes de aprendizagem online.

O estudo de Whipp e Chiarelli (2004) observou que estratégias de aprendizagem autorregulada utilizadas no ensino presencial eram facilmente aplicáveis em ambientes de aprendizagem a distância, porém com a necessidade de adaptação ao contexto, visto da utilização das tecnologias. No estudo de Terry e Doolittle (2006), há evidência de uma associação positiva entre a capacidade de gestão do tempo, atitude proativa, concentração, seleção de ideias principais e auxiliares de estudo e o desempenho global do aluno. Sendo a correlação mais forte entre a gestão do tempo e o desempenho do aluno.

Barnard-Brak, Lan e Paton (2010), utilizaram o Online Self-Regulated Learning Questionnaire (OLSQ), com alunos de graduação em EaD e seus resultados indicaram a presença de perfis distintos de aprendizagem autorregulada, como os de alunos com baixos escores de autorregulação, aqueles com autorregulação moderada e os com perfil alto de autorregulação. Além disso, indicaram uma relação entre o perfil de autorregulação e o desempenho acadêmico, sendo melhor sucedidos aqueles com perfil alto de autorregulação.

Utilizando o mesmo instrumento, Korkmaz e Kaya (2012) analisaram 222 alunos universitários frequentadores de cursos online e observaram que eles possuem altas habilidades de aprendizagem autorregulada, destacando a capacidade de estruturar o ambiente para o estudo como a mais utilizada e a menos utilizada o estabelecimento de metas.

Castro (2016) objetivou em seu trabalho, de caráter qualitativo e através de entrevistas semiestruturadas, evidenciar as características relacionadas à autorregulação da aprendizagem de estudantes do ensino superior na modalidade a distância. Verificou que esses estudantes desenvolveram ao longo do curso habilidades e atitudes típicas da autorregulação, como a utilização de estratégias cognitivas e metacognitivas, além da presente autonomia dos mesmos com relação aos estudos. 
Dessa forma, observa-se que esses estudos mostram que comportamentos de aprendizagem autorregulada são essenciais para que os alunos de EaD alcancem sucesso acadêmico e indicam que a compreensão desses comportamentos tem sido objeto de interesse crescente na literatura e importante para a melhoria do processo ensino e aprendizagem dessa modalidade de ensino.

\section{METODOLOGIA}

Esta pesquisa caracteriza-se como sendo de campo, descritiva e com abordagem quantitativa. Foi desenvolvida em um curso de Pedagogia na modalidade EaD de uma instituição particular do norte do Paraná, que possui 89.000 alunos matriculados, divididos em 583 polos, localizados nas cinco regiões do Brasil.

A partir desse universo, considerou-se um nível de confiança de $97 \%$ e margem de erro de $3 \%$, calculando-se a necessidade de uma amostra de 1.289 respondentes. O tipo de amostragem foi não probabilístico por adesão, sendo que se alcançou um número maior, totalizando 1.434 respostas válidas analisadas nessa pesquisa.

A coleta de dados foi realizada online, utilizando o programa Google Drive, sendo os tutores a distância os responsáveis por encaminhar aos alunos o link para participarem da pesquisa. Por meio deste sistema, o aluno inicialmente foi convidado a participar da pesquisa com a apresentação do Termo de Consentimento Livre e Esclarecido e, após o seu aceite, era direcionado ao instrumento a ser respondido.

$\mathrm{O}$ instrumento utilizado, refere-se a uma escala validada denominada Online Self-Regulated Learning Questionnaire (OSLQ) de Barnard-Brak, Lan e Paton (2010) - Questionário de Aprendizagem Autorregulada Online. Essa escala é do tipo Likert de 5 pontos, composta por 24 itens, divididos em seis fatores (Estabelecimento de Metas, Estruturação do Ambiente, Estratégias para as tarefas, Gerenciamento do Tempo, Procura de ajuda, Autoavaliação), na qual os participantes são orientados a assinalar a opção que representa melhor como eles se percebem em relação ao seu curso de educação a distância. Adicionalmente aos dados da escala foi utilizado um questionário sobre o perfil sociodemográfico dos alunos, contendo questões relativas à idade, sexo, estado civil, região em que reside, e semestre em que está matriculado.

A análise da escala OSLQ foi realizada pelo escore médio dos fatores avaliados. Assim, valores entre 1 e 2 indicam pouca frequência de autorregulação, entre 2,1 e 3,9, autorregulação moderada e entre 4 e 5, perfil alto de autorregulação (Barnard-Brak, Lan, e Paton, 2010). A análise desses dados permitiu verificar o quão autorregulado é o participante. Realizou-se ainda análise bivariada dos dados cruzando as respostas relacionadas à Autoregulação da Aprendizagem com os aspectos sociodemográficos e de identificação da série cursada pelo aluno. 


\section{RESULTADOS E DISCUSSÃO}

Para analisar a consistência interna da escala calculou-se o coeficiente alfa de Cronbach, que foi 0,89 , quando analisados todos os fatores da escala, o que indica uma boa consistência interna desse instrumento para a amostra pesquisada. Analisando os fatores separadamente, observou-se que o fator 1 (Estabelecimento de metas), o fator 2 (Estruturação do ambiente) e o fator 6 (Autoavaliação), mostraram coeficientes superiores a 0,70 , indicando uma consistência interna adequada. Já os fatores 3 (Estratégias para as tarefas), 4 (Gerenciamento do tempo) e 5 (Procura por ajuda) indicaram coeficientes compreendidos entre o,60 e o,69, revelando uma confiabilidade aceitável (Hair, Black, Babin, Anderson e Tatham, 2005).

Na pesquisa de Barnad-Brak, Lan e Paton (2010), o alfa de Cronbach no estudo 1 foi de 0,90 e no estudo 2 foi de 0,92 , valores semelhantes ao visto nessa amostra. No entanto, os coeficientes alfas de Cronbach verificados pelos autores em cada fator ficaram compreendidos acima de 0,85 nos dois estudos, valores superiores aos aqui mostrados.

Com relação a existência de correlação entre os fatores da escala obteve-se a matriz de correlação, através do coeficiente de Spearman, que indicou correlação significativa positiva entre todos os fatores. A correlação se apresentou moderada entre os fatores 1 (estabelecimento de metas) e 2 (estruturação do ambiente), entre os fatores 4 (gerenciamento do tempo) e 3 (estratégias para as tarefas), entre o fator 5 (procura por ajuda) e os fatores 3 (estratégias para as tarefas) e 4 (gerenciamento do tempo), e foi moderada também entre o fator 6 (autoavaliação) e os fatores 3 (estratégias para as tarefas), 4 (gerenciamento do tempo) e 5 (procura por ajuda). Os demais fatores apresentaram correlação pequena, porém definida (entre 0,21 e 0,40), não sendo observadas, no presente estudo, correlações altas, muito fortes ou leves entre os fatores.

Com base nos dados coletados a partir da aplicação do OSLQ foram calculados os valores mínimos e máximos, as médias e o desvio padrão, para cada Fator da Escala, conforme apresentados na tabela 1.

Tabela 1. Valores mínimos, máximos, médias e desvio padrão, referente a cada fator

\begin{tabular}{|c|c|c|c|c|}
\hline \multirow[b]{2}{*}{ Fatores } & \multicolumn{4}{|c|}{ Valores $(n=1.434)$} \\
\hline & Mínimo & Máximo & Média & $d p$ \\
\hline 1. Estabelecimento de Metas & 1 & 5 & 4,22 & 0,69 \\
\hline 2. Estruturação do Ambiente & 1 & 5 & 4,48 & 0,77 \\
\hline 3. Estratégias para as Tarefas & 1 & 5 & 3,80 & 0,81 \\
\hline 4. Gerenciamento do Tempo & 1 & 5 & 3,84 & 0,90 \\
\hline 5. Procura de Ajuda & 1 & 5 & 3,91 & 0,86 \\
\hline 6. Autoavaliação & 1 & 5 & 3,94 & 0,86 \\
\hline
\end{tabular}

Fonte: Autoras (2017). 
Observando os dados da tabela 1, e considerando os pressupostos da escala de Barnard-Brak, Lan e Paton (2010), pode-se afirmar que os alunos pesquisados apresentam um perfilalto de autorregulação, em relação aos fatores 1 (estabelecimento de metas) e 2 (estruturação do ambiente), uma vez que as médias foram de 4,22 (dp $=0,69)$ e $4,48(\mathrm{dp}=0,77)$, respectivamente, em 5 pontos possíveis.

Os fatores 3 (estratégias para as tarefas), 4 (gerenciamento do tempo), 5 (procura por ajuda) e 6 (autoavaliação) apresentaram médias abaixo de 4,0, indicando um perfil moderado de autorregulação dos alunos nesses fatores. $O$ fator 3 (estratégias para as tarefas), apresentou média 3,8 , no fator 4 (gerenciamento do tempo) a média foi de 3,84, o fator 5 (procura por ajuda) teve média 3,91 e o fator 6 (autoavaliação) teve média de 3,94.

Resultados semelhantes foram apresentados por Pavesi (2015), em cujo estudo, utilizando a mesma escala, encontrou perfil alto de autorregulação nos fatores 1 (média 4,3) e 2 (média 4,6) e perfil moderado de autorregulação nos fatores 3 (média 3,9), 4 (média 3,9), 5 (média 3,6) e 6 (média 3,9).

$\mathrm{Na}$ análise do fator 1 - Estabelecimento de Metas, notou-se que a maioria dos participantes dessa pesquisa, entre $46 \%$ e $55,4 \%$, responderam com "Concordo Totalmente" aos itens desse fator. Fato curioso foi encontrado no item 5 - Não comprometo a qualidade do meu trabalho por ele ser a distância, visto que, apesar da maioria $(55,4 \%)$ concordar totalmente com a afirmação, também foi a porcentagem maior de respostas em "discordo totalmente" (14,01\%). Esse dado pode supor a existência de um certo preconceito, ou até mesmo falta de comprometimento dos alunos com o ensino desenvolvido a distância.

De acordo com Almeida Filho (2015), uma parcela da população, incluindo alguns alunos de EaD, ainda não acreditam no potencial dessa modalidade de ensino, isso deve-se a dificuldades pessoais de adequar a aplicabilidade dos novos recursos tecnológicos de informação e comunicação na prática educacional.

O fator 2 - Estruturação do ambiente, foi o que obteve as maiores porcentagens de resposta em "concordo totalmente", com variação de 66,9\% a 69,7\%. Esse é um dado relevante, à medida que para o aluno de $\mathrm{EaD}$, a sala de aula pode ser sua residência, seu trabalho, bem como os computadores das instituições, e pensar sobre o melhor ambiente e organizá-lo de maneira adequada pode facilitar o aprendizado (Richardson e Swain, 2003).

O fator 3 - Estratégias para as tarefas foi o que obteve a menor média $(3,8)$ quando comparado com os outros fatores. Isso também é verificado em termos de proporção das respostas que ficaram divididas entre "concordo totalmente", "concordo parcialmente" e "indiferente", o que sugere que esse é um fator a ser melhor desenvolvido nos alunos pesquisados.

A estratégia mais utilizada pelos alunos, relatada por $52,4 \%$, é a de fazer anotações, seguida por preparar questões antes de entrar no chat (32,6\%), ler em voz alta $(32,3 \%)$ e trabalhar com problemas extras $(28,6 \%)$. A que recebeu mais 
respostas "discordo totalmente" foi a ler em voz alta (14\%) e 22,3\% são indiferentes quanto a preparar questões para participar dos chats.

No fator 4-Gerenciamento do tempo, as respostas dos três itens concentraramse em "concordo totalmente" e "concordo parcialmente", sendo o item com maior porcentagem o número 14 - dedico tempo extra de estudo ao curso, depois o item 16tento distribuir meu tempo de estudo, e por fim o item 15 - tento agendar o mesmo horário para estudar.

Nesse fator é visto que os alunos do curso pesquisado entendem que a flexibilidade de horários implica em responsabilidade, organização e gestão cuidadosa do tempo, a fim de conciliar as atividades do curso com suas demandas profissionais e pessoais e assim obter êxito no estudo (Whipp e Chiarelli, 2004).

Quando verificadas as respostas aos itens do fator 5 - Procura de Ajuda, observouse que o item 17 - procuro alguém que tenha conhecimento sobre o conteúdo, obteve $53 \%$ das respostas em "concordo totalmente", o item 19 - tento encontrar meus colegas pessoalmente, obteve $46,4 \%$, logo em seguida tem-se o item 18 - compartilho meus problemas com os colegas, com 39,2\% e o item 20 - sou persistente para obter ajuda do tutor por e-mail, com 33,4\%. Apesar de os alunos se encontrarem em um nível moderado de autorregulação nesse fator, o mesmo pode ser fomentado com ações de estímulo e pronto atendimento do tutor.

Para Ryan e Pintrich (1997) e Pintrich (2004), a estratégia de busca por ajuda é considerada uma estratégia comportamental, mas também é uma interação social que precisa ser incluída nos modelos de ensino que visam a promoção da autorregulação. Os autores destacam que alunos autorregulados sabem quando, por que e com quem procurar ajuda, sendo essa capacidade de decisão muito importante para o alcance do sucesso acadêmico.

A importância de buscar ajuda para solucionar suas dúvidas e problemas foram verificados no estudo de Whipp e Chiarelli (2004), no qual os autores apontam essa fonte de apoio, como uma das características dos alunos que se destacavam em termos de rendimento e aprendizagem, portanto um nível menor ou moderado em relação às estratégias de procura por ajuda pode influenciar diretamente na qualidade dos resultados obtidos por esses alunos, fato que merece maior atenção por parte das instituições.

Whipp e Chiarelli (2004) também verificaram que os alunos melhoraram sua aprendizagem com interações virtuais e pessoais com tutores e colegas, e também mencionaram que um frequente e oportuno feedback por parte dos tutores e professores são considerados essenciais para o sucesso da maioria dos alunos.

Em relação ao fator 6 - Autoavaliação verificou-se que as respostas dos alunos se concentraram em "concordo totalmente" e "concordo parcialmente", no entanto entre 9,9\% e 21,4\% são "indiferentes” ao uso dessa estratégia, o que sugere que esta, também deva ser contemplada e objetivada na organização do curso pesquisado.

Aautoavaliação está presenteem todosos modelos de aprendizagem autorregulada e de acordo com seus proponentes (Bandura, 1986; Pintrich, 2004; Rosário, 2004; 
Silva; Simão e Sá, 2004; Zimmerman, 2000) é crucial para a autorregulação a sua efetiva realização. É nesse momento que acontece a autorreflexão, o aluno emite um julgamento pessoal, se autoavalia, analisa sua atuação, bem como os resultados alcançados com relação as metas iniciais e a partir daí continua com os mesmos planos ou traça novos rumos para o seu processo de estudo e consequente aprendizagem.

Após a explanação da estatística descritiva, apresenta-se as correlações bivariadas entre os fatores da escala "Questionário de Aprendizagem Autorregulada Online" e o sexo, a idade, estado civil, região em que reside e semestre em que está matriculado o aluno.

A tabela 2 demonstra as médias e os desvios padrão no uso de estratégias de aprendizagem em função do sexo.

Tabela 2. Médias e desvios padrão relativas a cada fator em função do sexo

\begin{tabular}{|c|c|c|c|c|c|}
\hline & \multicolumn{2}{|c|}{$\begin{array}{c}\text { Feminino } \\
\mathrm{n}=1364(95,12 \%)\end{array}$} & \multicolumn{2}{|c|}{$\begin{array}{c}\text { Masculino } \\
\mathrm{n}=70(4,88 \%)\end{array}$} & \multirow[b]{2}{*}{$\mathbf{P}$} \\
\hline & Média & DP & Média & DP & \\
\hline Estabelecimento de Metas & 4,23 & 0,70 & 4,17 & 0,74 & 0,61 \\
\hline Estruturação do Ambiente & 4,50 & 0,75 & 4,19 & 1,02 & $0,01^{*}$ \\
\hline Estratégias para as tarefas & 3,81 & 0,81 & 3,69 & 0,92 & 0,30 \\
\hline Gerenciamento do Tempo & 3,85 & 0,89 & 3,76 & 1,04 & 0,76 \\
\hline Procura por ajuda & 3,92 & 0,86 & 3,81 & 1,00 & 0,49 \\
\hline Autoavaliação & 3,95 & 0,86 & 3,93 & 0,98 & 0,83 \\
\hline Média Geral & 4,04 & $\mathbf{0 , 8 1}$ & 3,92 & $\mathbf{0 , 9 5}$ & \\
\hline
\end{tabular}

* Valores com diferenças estatisticamente significativas $(\mathrm{p}<0,05)$

Fonte: Autoras (2017).

Apesar de verificar-se médias um pouco maiores em todos os fatores pelos respondentes do sexo feminino, o teste de Mann-Whitney apontou diferença estatisticamente significativa entre os sexos apenas no fator 2 (estruturação do ambiente). Corroboram esses dados, os encontrados por Korkmaz e Kaya (2012), que também analisaram o nível de autorregulação de aprendizagem dos alunos em função do sexo e não houve diferença significativa nas habilidades de aprendizagem autorregulada dos alunos em relação ao sexo.

A maior média encontrada para o sexo feminino foi no fator 2 (estruturação do ambiente) sendo esta 4,50 , já a menor $(3,81)$ foi no fator 3 (estratégias para as tarefas). No sexo masculino, o nível mais alto de autorregulação $(4,19)$ se deu também no fator 2 (estruturação do ambiente), e o mais baixo $(3,69)$ igualmente no fator 3 (estratégias para as tarefas), verificando-se uma semelhança no que se refere a autorregulação entre os sexos. 
Quando se analisa a média geral, podemos afirmar que o sexo feminino apresenta perfil alto de autorregulação $(4,04)$, enquanto o sexo masculino apresenta perfil moderado de autorregulação (3,92). No trabalho de Pavesi (2015), no qual a autora utilizou a mesma escala, as correlações encontradas foram semelhantes as do presente estudo, tendo os participantes do sexo feminino se apresentado como mais autorregulados do que os do sexo masculino em todos os fatores, apresentando média geral de 4,16 contra 3,88 .

Na tabela 3, são apresentadas as médias e desvios padrão relativas a cada fator, dessa vez em relação às faixas etárias.

Tabela 3. Médias e desvios padrão relativas a cada fator em função da faixa etária

\begin{tabular}{|c|c|c|c|c|c|c|c|c|c|}
\hline & \multicolumn{2}{|c|}{$\begin{array}{c}\text { Até } 20 \text { anos } \\
n=149 \\
(10,39 \%)\end{array}$} & \multicolumn{2}{|c|}{$\begin{array}{c}\text { De } 21 \text { a } 30 \\
\text { anos } \\
n=585 \\
(40,8 \%)\end{array}$} & \multicolumn{2}{|c|}{$\begin{array}{c}\text { De } 31 \text { a } 40 \\
\text { anos } \\
n=484 \\
(33,75 \%)\end{array}$} & \multicolumn{2}{|c|}{$\begin{array}{c}\text { Acima de } 41 \\
\text { anos } \\
\mathrm{n}=216 \\
(15,06 \%)\end{array}$} & \multirow[b]{2}{*}{ ? } \\
\hline & Média & DP & Média & DP & Média & DP & Média & DP & \\
\hline $\begin{array}{l}\text { Estabelecimento } \\
\text { de Metas }\end{array}$ & 4,15 & 0,71 & 4,18 & 0,72 & 4,23 & 0,69 & 4,36 & 0,64 & $0,004^{*}$ \\
\hline $\begin{array}{l}\text { Estruturação do } \\
\text { Ambiente }\end{array}$ & 4,40 & 0,85 & 4,47 & 0,76 & 4,45 & 0,81 & 4,68 & 0,62 & $0,000^{*}$ \\
\hline $\begin{array}{l}\text { Estratégias para } \\
\text { as tarefas }\end{array}$ & 3,79 & 0,77 & 3,76 & 0,83 & 3,78 & 0,84 & 3,96 & 0,76 & $0,021^{*}$ \\
\hline $\begin{array}{l}\text { Gerenciamento } \\
\text { do Tempo }\end{array}$ & 3,83 & 0,91 & 3,76 & 0,91 & 3,86 & 0,91 & 4,04 & 0,83 & $0,000^{*}$ \\
\hline $\begin{array}{l}\text { Procura por } \\
\text { ajuda }\end{array}$ & 3,79 & 0,98 & 3,92 & 0,86 & 3,89 & 0,86 & 4,06 & 0,81 & $0,025^{*}$ \\
\hline Autoavaliação & 3,87 & 0,90 & 3,96 & 0,89 & 3,92 & 0,86 & 4,04 & 0,78 & 0,267 \\
\hline Média Geral & $\mathbf{3 , 9 7}$ & $\mathbf{0 , 8 5}$ & 4,00 & $\mathbf{0 , 8 2}$ & 4,02 & $\mathbf{0 , 8 2}$ & 4,19 & 0,74 & \\
\hline
\end{tabular}

* Valores com diferenças estatisticamente significativas ( $\mathrm{p}<0,05)$

Fonte: Autoras (2017).

Como pode ser verificado na tabela 3 , o teste Kruskal-Wallis indicou diferenças estatisticamente significativas $(p<0,05)$ entre os fatores da escala em função das diferentes faixas etárias, com exceção do fator 6 (autoavaliação). Para identificar entre quais faixas etárias estas diferenças significativas ocorreram, foi realizado o teste de Dunnett em cada um dos fatores da escala.

A partir desse teste, observou-se que essas diferenças significativas ocorreram entre a faixa etária "até 20 anos" e a faixa etária "acima de 41 anos", nos fatores 1 (estabelecimento de metas), 2 (estruturação do ambiente) e 5 (procura por ajuda). Verificou-se também diferenças significativas entre a faixa etária "de 21 a 30 anos" e a faixa etária "acima de 41 anos", nos fatores 1 (estabelecimento de metas), 2 
(estruturação do ambiente), 3 (estratégias para as tarefas) e 4 (gerenciamento do tempo). Além de diferenças significativas serem apontadas entre a faixa etária "de 21 a 30 anos" e a faixa etária "acima de 41 anos", nos fatores 2 (estruturação do ambiente), 3 (estratégias para as tarefas) e 5 (procura por ajuda).

Analisando o fator 1 (estabelecimento de metas) a média vai aumentando linearmente entre as faixas etárias, sendo a menor $(4,15)$ encontrada na faixa etária "até 20 anos" e a maior $(4,36)$, na faixa etária "acima de 41 anos". O fator 2 (estruturação do ambiente) obteve as maiores médias em todas as faixas etárias, sendo a maior média $(4,68)$ vista na faixa etária "acima de 41 anos", seguida pela faixa etária "de 21 a 30 anos", com média de 4,47 e a faixa etária "de 31 a 40 anos", com média de 4,45 e por último a faixa etária "até 20 anos" com 4,40. Neste fator todas as faixas etárias apresentaram um nível alto de autorregulação.

Observando o fator 3 (estratégias para as tarefas) verifica-se que todas as faixas etárias apresentaram um nível moderado de autorregulação, sendo a menor média na faixa etária "de 21 a 30 anos" (3,76), em sequência a faixa etária "de 31 a 40 anos" (3,78), depois "até 20 anos" $(3,79)$ e maior média $(3,96)$ para faixa etária "acima de 41 anos". Nos fatores 4 (gerenciamento do tempo), 5 (procura por ajuda) e 6 (autoavaliação), apenas a faixa etária "acima de 41 anos" apresentou níveis altos de autorregulação. As demais faixas etárias mostraram-se moderadamente autorreguladas para os 3 fatores.

Verifica-se um incremento positivo, nas médias gerais, com relação a autorregulação conforme a faixa etária, o que indica que quanto maior a faixa etária, mais autorregulado se mostra o aluno. Essa ideia vai de encontro aos resultados obtidos nos estudos de Pavesi (2015), Ribeiro e Silva (2007) e Bortoletto (2011), que verificaram que com o decorrer dos anos, o indivíduo tende a aumentar uso de estratégias e tornar-se mais autorregulado.

A tabela 4 apresenta as médias e desvios padrão dos fatores da escala relacionados ao estado civil declarado pelos respondentes. 
Tabela 4. Médias e desvios padrão relativas a cada fator em função do estado civil

\begin{tabular}{|c|c|c|c|c|c|c|c|c|c|c|c|}
\hline & \multicolumn{2}{|c|}{$\begin{array}{c}\text { Solteiro } \\
\mathrm{n}=548 \\
(38,21 \%) \\
\end{array}$} & \multicolumn{2}{|c|}{$\begin{array}{c}\text { Casado } \\
\mathrm{n}=798 \\
(55,5 \%) \\
\end{array}$} & \multicolumn{2}{|c|}{$\begin{array}{c}\text { Divorciado } \\
n=61(4,25 \%)\end{array}$} & \multicolumn{2}{|c|}{$\begin{array}{c}\text { Separado } \\
\mathrm{n}=20 \\
(1,39 \%)\end{array}$} & \multicolumn{2}{|c|}{$\begin{array}{c}\text { Viúvo } \\
n=7 \\
(0,49 \%)\end{array}$} & \multirow[b]{2}{*}{ p } \\
\hline & Média & DP & Média & DP & Média & DP & Média & DP & Média & DP & \\
\hline $\begin{array}{l}\text { Estabelecimento } \\
\text { de Metas }\end{array}$ & 4,18 & 0,74 & 4,26 & 0,66 & 4,13 & 0,65 & 4,26 & 0,96 & 3,74 & 1,06 & 0,06 \\
\hline $\begin{array}{l}\text { Estruturação do } \\
\text { Ambiente }\end{array}$ & 4,43 & 0,82 & 4,53 & 0,72 & 4,55 & 0,75 & 4,46 & 0,93 & 3,93 & 1,43 & 0,10 \\
\hline $\begin{array}{l}\text { Estratégias para } \\
\text { as tarefas }\end{array}$ & 3,79 & 0,83 & 3,80 & 0,82 & 3,85 & 0,63 & 3,75 & 0,75 & 3,68 & 0,98 & 0,99 \\
\hline $\begin{array}{l}\text { Gerenciamento } \\
\text { do Tempo }\end{array}$ & 3,89 & 0,89 & 3,83 & 0,92 & 3,63 & 0,78 & 3,90 & 0,87 & 3,67 & 1,22 & 0,10 \\
\hline $\begin{array}{l}\text { Procura por } \\
\text { ajuda }\end{array}$ & 3,89 & 0,90 & 3,83 & 0,86 & 3,86 & 0,68 & 3,89 & 0,81 & 3,89 & 0,83 & 0,65 \\
\hline Autoavaliação & 3,95 & 0,91 & 3,97 & 0,83 & 3,75 & 0,85 & 3,72 & 0,96 & 3,86 & 0,99 & 0,16 \\
\hline Média Geral & 4,02 & 0,84 & $4, \mathbf{0 3}$ & $\mathbf{o , 8 0}$ & 3,96 & 0,72 & 3,99 & $\mathbf{0 , 8 8}$ & 3,79 & 1,08 & \\
\hline
\end{tabular}

Fonte: Autoras (2017).

Quando analisados os fatores da escala em função do estado civil, não se apresentaram diferenças estatisticamente significativas com o teste Kruskal-Wallis. No entanto, quando se verifica as médias gerais, tem-se que solteiros e casados possuem níveis altos de autorregulação, 4,02 e 4,03 respectivamente, enquanto os divorciados $(3,96)$, separados $(3,99)$ e viúvos $(3,79)$ apresentam-se moderadamente autorregulados.

As maiores médias $(4,26)$ no fator 1 (estabelecimento de metas) ficaram com os casados e separados, em seguida com 4,18 estão os solteiros, com 4,16 os divorciados, todos com alto nível de autorregulação. Já a menor média $(3,74)$, foi apresentada pelos viúvos, considerando-se esse um nível moderado de autorregulação.

No fator 2 (estruturação do ambiente), os divorciados apresentaram a maior média $(4,55)$, seguido pelos casados $(4,53)$, separados $(4,46)$ e solteiros $(4,43)$ com alto nível de autorregulação e mais uma vez os viúvos obtiveram a menor média $(3,97)$, sendo considerados moderadamente autorregulados.

As menores médias, de todos os estados civis, foram constatadas no fator 3 (estratégias para as tarefas), apresentando um nível moderado de autorregulação para todos. Esse nível moderado, também foi verificado para todos os estados civis, nos fatores 4 (gerenciamento do tempo), 5 (procura de ajuda) e 6 (autoavaliação).

$\mathrm{Na}$ tabela 5 podem ser visualizadas as médias e desvios padrão dos fatores da escala relacionados a região em que reside o estudante. 
Tabela 5. Médias e desvios padrão relativas a cada fator em função da região em que reside o estudante

\begin{tabular}{|c|c|c|c|c|c|c|c|c|c|c|c|}
\hline & \multicolumn{2}{|c|}{$\begin{array}{c}\text { Sul } \\
n=291 \\
(20,29 \%)\end{array}$} & \multicolumn{2}{|c|}{$\begin{array}{c}\text { Sudeste } \\
n=474 \\
(33,05 \%)\end{array}$} & \multicolumn{2}{|c|}{$\begin{array}{c}\text { Centro } \\
\text { Oeste } \\
\mathrm{n}=208 \\
(14,5 \%)\end{array}$} & \multicolumn{2}{|c|}{$\begin{array}{c}\text { Norte } \\
n=194 \\
(13,52 \%)\end{array}$} & \multicolumn{2}{|c|}{$\begin{array}{c}\text { Nordeste } \\
n=267 \\
(18,62 \%)\end{array}$} & \multirow[b]{2}{*}{ p } \\
\hline & Média & DP & Média & DP & Média & DP & Média & DP & Média & DP & \\
\hline $\begin{array}{l}\text { Estabelecimento } \\
\text { de Metas }\end{array}$ & 4,26 & 0,68 & 4,21 & 0,71 & 4,20 & 0,71 & 4,21 & 0,66 & 4,24 & 0,71 & 0,71 \\
\hline $\begin{array}{l}\text { Estruturação do } \\
\text { Ambiente }\end{array}$ & 4,49 & 0,72 & 4,49 & 0,81 & 4,37 & 0,88 & 4,55 & 0,67 & 4,51 & 0,72 & 0,45 \\
\hline $\begin{array}{l}\text { Estratégias para } \\
\text { as tarefas }\end{array}$ & 3,81 & 0,79 & 3,75 & 0,84 & 3,89 & 0,77 & 3,91 & 0,79 & 3,74 & 0,85 & 0,07 \\
\hline $\begin{array}{l}\text { Gerenciamento } \\
\text { do Tempo }\end{array}$ & 3,77 & 0,94 & 3,81 & 0,91 & 3,89 & 0,91 & 3,99 & 0,84 & 3,84 & 0,88 & 0,10 \\
\hline $\begin{array}{l}\text { Procura por } \\
\text { ajuda }\end{array}$ & 3,99 & 0,78 & 3,83 & 0,91 & 3,95 & 0,89 & 3,95 & 0,84 & 3,94 & 0,88 & 0,17 \\
\hline Autoavaliação & 3,93 & 0,88 & 3,85 & 0,89 & 3,95 & 0,92 & 4,02 & 0,80 & 4,08 & 0,80 & $0,00^{*}$ \\
\hline Média Geral & 4,04 & 0,79 & 3,99 & $\mathbf{0 , 8 4}$ & 4,04 & $\mathbf{0 , 8 4}$ & 4,10 & 0,76 & 4,05 & $\mathbf{0 , 8 0}$ & \\
\hline
\end{tabular}

* Valores com diferenças estatisticamente significativas ( $\mathrm{p}<0,05)$

Fonte: Autoras (2017).

Após a verificação pelo teste Kruskal-Wallis, observa-se na tabela 5 que a única diferença estatisticamente significativa foi no fator 6 (autoavaliação), cuja maior média foi 4,08 apresentada pela região Nordeste, seguida pela região Norte $(4,02)$, ambas com alto nível de autorregulação. A região Centro-Oeste teve média de 3,95, a Sul de 3,93 e a Sudeste de 3,85, sendo considerados moderadamente autorregulados. A partir do teste de Dunnett, observou-se que estas diferenças significativas ocorreram entre as regiões Nordeste e Sudeste.

Nos fatores 1 (estabelecimento de metas) e 2 (estruturação do ambiente), todas as regiões apresentaram alto nível de autorregulação, sendo a maior média $(4,49)$ alcançada pela região Sul no fator 2 e a menor $(4,20)$ pela região Centro-Oeste no fator 1.

Seguindo o que foi encontrado nas demais correlações, os fatores 3 (estratégias para as tarefas), 4 (gerenciamento do tempo) e 5 (procura por ajuda) apresentaram níveis moderados de autorregulação.

Na tabela 6, podem-se observar as médias e desvios padrão quando relacionados os fatores da escala com o semestre em que o aluno se encontra matriculado. 
Tabela 6. Médias e desvios padrão relativas a cada fator em função do semestre em que está matriculado

\begin{tabular}{|c|c|c|c|c|c|c|c|c|}
\hline & Fatores & 1 & 2 & 3 & 4 & 5 & 6 & $\begin{array}{l}\text { Média } \\
\text { Geral }\end{array}$ \\
\hline \multirow{2}{*}{$1^{\circ}$ Semestre } & Média & 4,17 & 4,44 & 3,84 & 3,96 & 3,95 & 3,96 & 4,05 \\
\hline & DP & 0,66 & 0,88 & 0,73 & 0,89 & 0,82 & 0,94 & $\mathbf{0 , 8 2}$ \\
\hline \multirow{2}{*}{$2^{\circ}$ Semestre } & Média & 4,27 & 4,60 & 3,83 & 3,94 & 3,88 & 4,08 & 4,10 \\
\hline & DP & 0,65 & 0,63 & 0,78 & 0,91 & 0,93 & 0,83 & 0,78 \\
\hline \multirow{2}{*}{$3^{\circ}$ Semestre } & Média & 4,16 & 4,39 & 3,74 & 3,78 & 3,78 & 3,81 & 3,94 \\
\hline & DP & 0,77 & 0,96 & 0,86 & 0,96 & 0,95 & 0,92 & $\mathbf{0 , 9 0}$ \\
\hline \multirow{2}{*}{$4^{\circ}$ Semestre } & Média & 4,26 & 4,55 & 3,77 & 3,84 & 3,93 & 3,96 & 4,05 \\
\hline & DP & 0,64 & 0,66 & 0,80 & 0,85 & 0,85 & 0,83 & $\mathbf{0 , 7 7}$ \\
\hline \multirow{2}{*}{$5^{\circ}$ Semestre } & Média & 4,25 & 4,59 & 3,87 & 3,86 & 3,85 & 3,89 & 4,05 \\
\hline & DP & 0,73 & 0,73 & 0,89 & 0,98 & 0,94 & 0,97 & $\mathbf{0 , 8 7}$ \\
\hline \multirow{2}{*}{$6^{\circ}$ Semestre } & Média & 4,18 & 4,43 & 3,83 & 3,77 & 3,88 & 3,86 & 3,99 \\
\hline & DP & 0,73 & 0,84 & 0,81 & 0,95 & 0,89 & 0,90 & $\mathbf{0 , 8 5}$ \\
\hline \multirow{2}{*}{$7^{\circ}$ Semestre } & Média & 4,19 & 4,49 & 3,72 & 3,99 & 4,11 & 4,06 & 4,09 \\
\hline & DP & 0,70 & 0,74 & 0,86 & 0,85 & 0,65 & 0,85 & $\mathbf{0 , 7 7}$ \\
\hline \multirow{2}{*}{$8^{\circ}$ Semestre } & Média & 4,22 & 4,39 & 3,83 & 3,82 & 4,01 & 3,97 & 4,04 \\
\hline & DP & 0,74 & 0,80 & 0,85 & 0,89 & 0,80 & 0,83 & $\mathbf{0 , 8 1}$ \\
\hline $\mathbf{P}$ & & 0,81 & 0,08 & 0,81 & 0,32 & 0,44 & 0,08 & \\
\hline
\end{tabular}

Fonte: Autoras (2017).

O teste Kruskal-Wallis mostrou não haver diferenças estatisticamente significativas quando relacionados os semestres com os fatores da escala. Nesse caso, ao contrário do que se suponha inicialmente, não ocorreu um incremento do nível autorregulatório conforme o avanço dos semestres do curso.

Analisando-se as médias gerais, nota-se que os participantes do $2^{\circ}$ semestre são considerados altamente autorregulados, com média de 4,10, assim como os participantes do $7^{\circ}$ semestre, com média de 4,09, e os participantes dos $1^{\circ}, 4^{\circ}$ e $5^{\circ}$ semestres com médias de 4,05, seguidos pelos participantes do $8^{\circ}$ semestre com 4,04. A menor média foi registrada pelos participantes do $3^{\circ}$ semestre, 3,99, mostrando-se moderadamente autorregulados.

Pode-se inferir que, na medida em que os alunos avançam nos semestres, percebem que as estratégias iniciais utilizadas na realização das atividades do curso são suficientes para prosseguir não promovendo assim a sua autorregulação e desenvolvimento de novas estratégias. Isto pode decorrer das propostas de ensino utilizadas, sejam facilitando ou dando novas oportunidades de tempo e outras atividades, quando o aluno não tirar a nota necessária. 


\section{CONSIDERAÇÕES}

A presente pesquisa objetivou analisar o perfil da aprendizagem autorregulada dos alunos matriculados no curso de Pedagogia ofertado a distância de uma instituição particular localizada no Norte do Paraná.

Observou-se que, de maneira geral, os alunos pesquisados apresentam um bom nível de autorregulação, sendo esta uma condição necessária para o êxito na EaD. $\mathrm{O}$ fator estruturação do ambiente, que envolve estratégias como procurar um local de estudos que evite distrações e proporcione um ambiente confortável e escolher horários mais propícios para realizar os estudos apresentou a maior média entre os fatores, seguido pelo fator estabelecimento de metas, ambos indicando um perfil alto de autorregulação. Os fatores gerenciamento do tempo, procura por ajuda e autoavaliação, apresentaram um perfil moderado de autorregulação. Em relação ao uso das estratégias para as tarefas, que contemplam estratégias operacionais como fazer anotações, ler em voz alta, preparar questões e resolver problemas extras, os resultados mostraram um nível moderado de autorregulação, porém o mais baixo entre os fatores. Assim, ressalta-se a importância de que o uso destas estratégias seja trabalhado junto aos alunos, de forma a melhorar o nível de autorregulação em relação a elas. Quanto maior a faixa etária mais autorregulado se apresentou o aluno. Nas relações entre os fatores da escala com o sexo, estado civil, região do país e semestre, não foram encontradas diferenças estatisticamente significativas.

A partir dos resultados aqui apresentados, observa-se, como contribuições teóricas / empíricas, que a presente pesquisa possa auxiliar o corpo docente e os tutores do curso pesquisado e similares a reconhecerem o nível de autorregulação da aprendizagem dos alunos, podendo orientá-los em relação a quais estratégias devem estimular/ensinar a seus alunos, melhorando dessa forma o processo de ensino e aprendizagem, possibilitando assim uma melhoria de suas práticas pedagógicas e uma maior articulação dos projetos pedagógicos aos processos educacionais de aprendizagem no contexto de cursos ofertados à distância.

Vale destacar que a análise do presente trabalho foi realizada a partir de dados obtidos por autorrelato, que, apesar de ser um método importante nas pesquisas de autorregulação, pode levar o aluno a escolher variáveis socialmente desejáveis sobre suas formas de estudo, nem sempre condizendo com a realidade.

Como continuidade desta pesquisa, sugere-se a ampliação deste estudo com cursos de outras áreas ofertados a distância, pela própria instituição de ensino e também em outras instituições, para se verificar diferenças e/ou similaridades com os resultados aqui apresentados. Outra sugestão é que novas pesquisas sejam desenvolvidas a respeito desta temática, em que possam ser utilizados também outros instrumentos de investigação, como por exemplo, observação e entrevistas, possibilitando assim, dados quantitativos e qualitativos para a análise sobre a autorregulação da aprendizagem de alunos de EaD. 


\section{REFERÊNCIAS}

Almeida Filho, C. C. P. (2015). O avanço da educação a distância no Brasil e a quebra de preconceitos: uma questão de adaptação. Revista Multitexto, 3(1), 1420.

Alves, L. (2011). Educação à distância: conceitos e história no Brasil e no mundo. Revista Brasileira de Aprendizagem Aberta e a Distância, 10, 83-92.

Associação Brasileira de Educação a Distância - ABED. (2018). Censo EAD. BR 2017: relatório analítico da aprendizagem a distância no Brasil. Curitiba: InterSaberes. Recuperado de http://abed.org.br/arquivos/CENSO EAD BR 2018 digital completo.pdf

Bandura, A. (1986). Social foundations of thought and action: a social cognitive theory. Englewood Cliffs, NJ: PrenticeHall.

Barnard-Brak, L., Lan, W. Y., y Paton, V. O. (2010). Profiles in self-regulated learning in the online learning environment. International Review of Research in Open and Distance Learning, 11(1), 14956.

Belloni, M. L. (2002). Ensaio sobre a educação a distância no Brasil. Educação \& Sociedade, 23(78), 117-42.

Benício, E. R. (2010). A EaD na formação de professores: uma tendência contemporânea. Recuperado de http://www.partes.com.br/educacao/ eadformacao.asp

Bergamin, P. B., Ziska, S., Werlen, E., y Siegenthaler, E. (2012). The relationship between flexible and self-regulated learning in open and distance universities. The International Review of Research in Open and Distance Learning, 13(2), 101123.

Borletto, D. (2011). Estratégias de aprendizagem e de regulação emocional de estudantes dos cursos de formação de professores (Master's thesis). Universidade Estadual de Campinas.

Castro, R. F. (2016) Autorregulação da aprendizagem no ensino superior a distância: o que dizem os estudantes? Revista Brasileira de Ensino Superior, 2(2), 15-26.

Dias, R. A., y Leite, L. S. (2010). Educação à distância: da legislação ao pedagógico. Petrópolis: Vozes.

Góes, N. M., y Alliprandini, P. M. Z. (2013). $O$ uso de estratégias de aprendizagem e o papel do tutor: análise da produção científica disponível nos sites Scielo, ERIC e RIED no período de 2003 a 2013. Artigo apresentado no Congresso Nacional de Educação EDCERE, 11, Curitiba.

Góes, N. M., y Alliprandini, P. M. Z. (2014). Análise das estratégias de aprendizagem cognitivas, metacognitivas, autorregulatórias e comportamentais utilizadas por alunos de um curso de pedagogia ofertado a distância. Artigo apresentado no ANPED SUL 10, Florianópolis.

Hair, J. F., Black, W., Babin, B. J., Anderson, R. E., y Tatham, R. L. (2005). Análise multivariada de dados. Porto Alegre: Bookman.

Korkmaz, O., y Kaya, S. (2012). Adapting Online Self-Regulated Learning Scale into Turkish. Turkish Online Journal of Distance Education, 13(1), 52-67.

Lessa, S. C. F. (2011). Os reflexos da legislação de educação a distância no Brasil. Revista Brasileira de Aprendizagem Aberta e a Distância, 10, 17-28.

Lima, M. das G. S. (2003). Educação à distância: conceituação e historicidade. Revista Trilhas, 4(1), 61-77.

Lynch, R., y Dembo, M. (2004). The relationship between self-regulation and online learning in a blended learning contexto. International Review of 
Research in Open and Distance Learning, 5(2), 1-16.

Pavesi, M. A. (2015). Análise da aprendizagem autorregulada de alunos de cursos à distância em função das áreas de conhecimento, faixa etária e sexo (Master's thesis). Universidade Estadual de Londrina.

Piccoli, G., Ahmad, R., y Ives, B. (2001). Webbased virtual learning environments: a research framework and a preliminary assessment of effectiveness in basic it skills training. MIS Quarterly, 25(4), 40126.

Pintrich, P. R. (2004). A conceptual framework for assessing motivation and self-regulated learning in college students. Educational Psychology Review, 16(4), 385-406.

Ribeiro, I. S., y Silva, C. F. (2007). Autorregulação: diferenças em função do ano e área em alunos universitários. Psicologia: Teoria e Pesquisa, 23(4), 443448.

Richardson, J., y Swain, K. (2003). Examining social presence in online courses in relation to students' perceived learning and satisfaction. Journal of Asychronous Learning Networks, 7(1), 68-88.

Rosário, P. (2004). Estudar o estudar: as (des) venturas dosbbb testas. Porto: Porto Editora.

Ryan, A., y Pintrich, P. R. (1997). Should I ask for help? - the role of motivation and attitudes in adolescents help seeking in math class. Journal of Educational Psychology, 89, 329-341.

Sabourin, J., Mott, B., y Lester, J. (2012). Early prediction of student self-regulation strategies by combining multiple models.
In Y. Kalina, et al, 5th International conference on educational data mining, pp. 19-21.

Silva, A. L., Simão, A. M. da V., y Sá, I. (2004). Autorregulação da aprendizagem: estudos teóricos e empíricos. Intermeio, 10(19), 59-74.

Simão, A. M. V., y Frison, L. M. B. (2013). Autorregulação da aprendizagem: abordagens teóricas e desafios para as práticas em contextos educativos. Cadernos de Educação, 45, 2-20.

Terry, K. P., y Doolittle, P. (2006). Fostering self-regulation in distributed learning. College Quarterly, 9(1), 1-8.

Testa, M. G., y Luciano, E. M. (2010). A influência da autorregulação dos recursos de aprendizagem na efetividade dos cursos desenvolvidos em ambientes virtuais de aprendizagem na internet. Revista Eletrônica de Administração, 16(2), 481-513.

Vovides, Y. et al. (2007). The use of e-learning course management system to support learning strategies and to improve selfregulated learning. Educational Research Review, 2(1), 64-74.

Whipp, J., y Chiarelli, S. (2004). Selfregulation in a web-based course: a case study. Educational Technology Research and Development, 52(4), 5-22.

Zimmerman, B. (2000). Self-efficacy: an essential motive to learn contemporary educational. Contemporary Educational Psychology, 25(1), 82-91.

Zimmerman, B. J. y Schunk, D. H. (2011). Self-regulated and Performance: An introduction and an overview. In B. Zimmerman y D. H. Schunk, Handbook of self-regulation of learning band performance, 1-12. 


\section{PERFIL ACADÊMICO E PROFISSIONAL DAS AUTORAS}

Juliana Gomes Fernandes. Mestre em Metodologias para o Ensino de Linguagens e suas Tecnologias, pela Universidade Norte do Paraná (UNOPAR). Docente do Instituto Federal do Paraná - Campus Londrina (IFPR). Linhas de trabalho: ensino, ensino técnico e ensino a distância.

E-mail: juliana.fernandes@ifpr.edu.br

Endereço:

Instituto Federal do Paraná -Campus Londrina

Rua João XXII, 600 - CEP 86060-370

Londrina/PR, Brasil

Luciane Guimarães Batistella Bianchini. Pós-Doutora em Psicologia pelo Programa de Pós-Graduação da Universidade Estadual Paulista (UNESP). Docente do Programa de Mestrado em Metodologias para o Ensino de Linguagens e suas Tecnologias da Universidade Norte do Paraná (UNOPAR). Linhas de trabalho: ensino a distância, utilização de tecnologias na educação.

E-mail: luciane.bianchini@kroton.com

Endereço:

Rua São Vicente, 165, Centro - CEP 86026-030

Londrina/PR, Brasil

Paula Mariza Zedu Alliprandini. Pós-Doutora pelo Departamento de Psicologia da "Cornell University". Professor Associado a do Departamento de Educação e Programa de Pós-Graduação em Educação da Universidade Estadual de Londrina (UEL). Linhas de trabalho: autorregulação da aprendizagem, estratégias de aprendizagem, percepção, memória e motivação, discutindo a contribuição destas temáticas no diagnóstico e intervenção frente ao processo de aprendizagem em contextos escolares.

E-mail: paulaalliprandini@uel.br

Endereço:

Universidade Estadual de Londrina, Campus Universitário, Departamento de Educação.

Rodovia Celso Garcia Cid, Pr 445 Km 380

Londrina/PR, Brasil

Data de recebimento do artigo: $03 / 12 / 2018$

Data de aprovação do artigo: 06/07/2019

Data de aprovação para maquetação: 07/08/2019 